Operations Research and Applications : An International Journal (ORAJ), Vol.3, No.2, May 2016

\title{
AN INTEGRATED VENDOR AND BUYER INVENTORY MODEL WITH INVESTMENT FOR QUALITY IMPROVEMENT AND SETUP COST REDUCTION
}

\author{
M. Vijayashree ${ }^{1 *}$, R. Uthayakumar ${ }^{2}$ \\ Department of Mathematics, \\ The Gandhigram Rural Institute - Deemed University, \\ Gandhigram - 624 302. Dindigul, Tamil Nadu, India.
}

\begin{abstract}
This paper attempts to determine optimal production run time and joint capital investment in setup cost reduction and process quality for production system such that the total cost is minimized. We assumed that the setup cost and process quality are logarithmic function. Main focus for this paper is the setup cost reduction. The proposed model is based on the total cost for the single vendor and single buyer. Then, an algorithm procedure is developed in order to find the optimal solution and numerical example is used to demonstrate the benefits of the model. By logarithmic investment function, the optimal investment for process quality and setup cost reduction investment also are obtained. Our objective is to develop an algorithm to determine the order quantity, setup cost, process quality and number of deliveries simultaneously, so that the total cost incurred is minimum.
\end{abstract}

\section{KEYWORDS}

Integrated inventory model, Cost reduction, Logarithmic function, Investment for quality improvement.

\section{INTRODUCTION}

Inventory is frequently the major item in the current assets group and must be exactly counted and valued at the end of each accounting period to determine a company's profit or loss. Inventory management is about knowing what you have in your storehouse and where your supply is placed. However, unless it's incorporated with your back-office systems, an inventory management system unaccompanied can't successfully optimize your inventory, nor make sure the inventory benefit value on your economic reports matches what is actually in stock at least not without manual interference and settlement.

Arithmetic equation or formula that helps a firm in formative the economic order quantity and the frequency of ordering, to uphold goods or services graceful to the customer without intermission or delay. The co-maker idea has developed into established preparation in numerous successful international production organizations. The basic tenet of this viewpoint is that vendor (supplier) and purchaser are importance chain partners in manufacturing and delivering a high quality product to the purchaser's customers. This point of view has led to the growth of a class of inventory models known as integrated or joint economic lot size (JELS) models. These models

DOI : 10.5121/oraj.2016.3201 
Operations Research and Applications : An International Journal (ORAJ), Vol.3, No.2, May 2016

consist of lot size method based on the combined optimization of vendor and buyer costs. Supply chain management (SCM) is the organization of the run of goods and services. It includes the movement and storage of raw materials, work-in-process inventory, and finished goods from point of origin to point of consumption. SCM often requires the integration of inter-and intraorganizational relations and organizations of different types of flows within the complete supply chain structure. SCM helps firms in integrating their industries by collaborating with other worth chain partners to meet the random demand of the end user. SCM seems to be a rising area of interest amongst researchers and practitioners from varied disciplines. Just-In-Time (JIT) has been playing a key position in supply chain environments. Just in time (JIT) is an inventory plan companies utilize to add to effectiveness and reduce misuse by receiving supplies only as they are required in the construction procedure, thereby reducing inventory costs.

\section{LITERATURE REVIEW}

In the past, the majority of the inventory model researchers considered only the self-governing sight point. In history, economic order quantity (EOQ) and economic production quantity (EPQ) were pleasuring independently from the point of views of the buyer or the vendor. However, in supply chain environment, the organization of all the partners is the key to capable management of a supply chain to achieve global optimality. Research on coordinating supply chains is currently very popular. For the period of the previous few years, the concept of incorporated vendor-buyer inventory management has attracted considerable attention, accompanying the growth of Supply Chain Management (SCM).

In the current SCM environment, corporations are using JIT manufacture to increase and preserve a spirited benefit. JIT needs strength of cooperation between the buyer and the vendor and it has been shown that forming a corporation among the buyer and the vendor is supportive in getting tangible benefits for both parties [7]. In this composite environment, winning corporations have dedicated sizeable attention to falling inventory cost and improving quality simultaneously. Goyal [9] optional a joint best economic lot size representation with the purpose of minimizing the total relevant costs for together the vendor and the buyer, in which a supportive understanding is enforced by some contractual agreement. Banerjee [1] proposed an optimum economic lot size model by assuming that the vendor produces to order for a buyer on a lot-for-lot basis under deterministic circumstances. Goyal [9] comprehensive the model of Banerjee [1] by relaxing the assumption of the lot-for-lot policy of the vendor and showed that his joint optimum economic lot size model where the vendor's economic production quantity per cycle is an integer multiple of the buyer's purchase quantity provides a lower or equal joint total relevant cost when compared to Banerjee's model [1] Goyal and Gupta [5] reviewed the related literature on models which provide a coordinating mechanism between the buyer and the vendor. Lu [19] collected Goyal's [10] hypothesis of accomplishment a batch before a delivery is started and explored a model that permitted shipments to take place any time during the production cycle with the delivery quantity to the buyer is known. Due to the recurrent shipping policy planned by the model, the transportation cost should be taken into account in the relevant cost to investigate the relationship between number of shipments and inventory level. The integrated inventory administration idea has established a huge contract of notice, additional the improvement of Supply Chain Management. Investigate on the integrated vendor-buyer joint inventory problem focused primarily on the creative consignment agenda in terms of the number and size of the batches relocate between in cooperation parties under perfect quality (see, e.g. Goyal, [4]; Goyal and Nebebe, [6]; Ha and Kim, [11]; Kelle et al, [16]; Lu [19]; Lin and Lin, [18], Goyal ([8], [4]), Lu 
Operations Research and Applications : An International Journal (ORAJ), Vol.3, No.2, May 2016

[19], Hill ([12], [13]), Goyal and Nebebe [6], and Kelle et al. [16]). The above mentioned references did not describe the relationship between production batch and quality. In the current year, Vandana and Sharma [33] have investigated an inventory model for non-instantaneous deteriorating items with quadratic demand rate and shortages under trade credit policy. Vandana and Sharma [34] have urbanized an EOQ model for retailer's partial permissible delay in payment linked to order quantity with shortages. Vandana and Sharma [35] have considered an EPQ inventory model for non-instantaneous deteriorating items under trade credit policy.

Inventory expenses are the expenses related to storing and uphold its inventory over a certain stage of time. Setup cost is the major part of the inventory organization and organization. Setup cost is related with expenses incurred in surroundings up a machine, work center, or assembly line, to switch from one production career to the subsequently. Traditionally, the economic order quantity has been a major tool used in production planning and inventory control. The classical economic order quantity assumes that setup cost is fixed and constant. An interesting possibility that has been considered in recent research is that of investment in reduction of setup cost. That is, setup cost is assumed to be variable rather than constant. The Japanese experience teaches us that setup times may be markedly reduced as part of ongoing program of improvement. This observation has led many researchers [1, 25, 23, 28 and 27] to investigate the impact of investing in setup cost reduction on the policy variables of inventory system. Paknejad and Affisco [24] developed an analysis of setup cost reduction in a two stage system. In numerous sensible situations, setup cost can be controlled and reduced through various effects such as worker training, procedural changes and specialized equipment acquisition. If the setup cost per order could be reduced effectively, the total relevant cost per unit time could be automatically improved. Through the Japanese experience of using JIT production and benefits associated with efforts to reduce the ordering cost can be clearly perceived. In recent years, several authors have studied inventory models with controllable setup cost and lead time.

Quality improvement is a good move toward to the investigation of exterior and prepared efforts to improve it. Quality Improvement is a systematic move toward to making changes that direct to better patient outcomes (health), stronger system presentation (care) and enhanced dedicated enlargement. It draws on the combined and stable efforts of all stakeholders' health care specialized, patients and their families, researchers, planners and educators to make better and sustained development. In the dynamic, competitive environment, successful companies have devoted considerable attention to reduce inventory cost and lead time and improving quality simultaneously. The incorporated inventory management scheme is a regular practice in the global markets and provides economic advantages for together the vendor and the buyer. Recently, the lot sizing problem has established considerable attention. But the bulk of analyses have always assumed implicitly perfect quality of products. Product quality, however, is not always perfect, and is usually a function of the state of the manufacture process. When the production process is in control the items produced would be of high or wonderful excellence. As time goes on, the procedure may get worse and begin to manufacture defective items. Thus, the relationship between production lot size and the quality of the manufactured goods may be important. The effect of process deterioration on the optimal production run time was studied by Poterus [20] and Rosenblatt and Lee [30]. Porteus [29] assumed that the production process can shift to the out-of-control state with a given probability each time it produces an item and once it goes out of control, it would begin to produce defective products. Rosenblatt and Lee [30] analyze the holder when the system deteriorates throughout the production process and produces some proportion of defective items. Unlike the assumption of Rosenblat and Lee [21] and Porteus 
Operations Research and Applications : An International Journal (ORAJ), Vol.3, No.2, May 2016

[29], Salameh and Jaber [31] assumed that the defective items could be sold in a single batch at the end of a $100 \%$ screening process and found that the economic lot size quantity tended to increase as the average percentage of imperfect quality items increased. Cardenas- CardenasBarron [2] where an error appearing on Salameh and Jaber [31] was corrected. Thereafter, Chan et al. [3] proposed a non-shortage model similar to that in Salameh and Jaber [31], where products are classified as good quality, good quality after alternative, defective value and piece. Rosenblatt and Lee [30] suppose that the elapsed time until the production process shift is a random variable and is exponentially distributed, and derive an approximated optimal production run time in their models. We assume that the relationship between setup cost reduction (or process quality improvement) and capital investment can be described by the logarithmic investment function. For example, see Paknejad and Affisco [22], Nasri et al. [20], Sarker and Coates [32], and Hofmann [14].

Pan and Yang [26] presented an integrated supplier-purchaser model focused on the benefit from lead time while exclusive of quality linked issues. However, defective items are often and inevitably produced in real production systems. These defective items must be discarded, repaired, reworked, or, if they have reached the purchaser, refunded. In all cases, considerable expenses are incurred Ouyang et al. [22]. Porteus [29] and Rosenblatt and Lee [30] first presented the significant relationship between quality improvement related literatures; for example, see Keller and Noori [17], Ouyang and Chang [21] and Ouyang et al. [22]. In the real world, it is more significant to take the worth related cost into account in formative the optimal ordering policy.

The remainder of this paper is organized as follows. Section 3 describes the notation used throughout this paper. In Section 4, describes the assumptions used throughout this paper. Model formulation is given in the section 5. Solution method is given in the section 6 . In section 7, an efficient algorithm is urbanized to obtain the optimal answer. A descriptive numerical example is provided in the section 8 . Finally, we draw conclusion in section 9.

\section{Notations}

To expand the proposed model, we take on the following notations:

$Q \quad$ Order quantity of the buyer. (Decision variable).

$\theta \quad$ Probability of the vendor's production process that can go out-of-control (Decision variable).

$\theta_{0} \quad$ Original probability of the vendor's production process the can go out-of-control.

$m$ The integer of deliveries of the product delivered from the vendor to the buyer in one production

cycle, a positive integer.

$D \quad$ Expected demand per unit time.

$P \quad$ Production rate in units per unit time $(P>D)$.

A Buyer's ordering cost per order.

$S \quad$ Vendor's setup cost per setup (Decision variable).

$S_{0} \quad$ Original vendor's setup cost for each production run. 
Operations Research and Applications : An International Journal (ORAJ), Vol.3, No.2, May 2016

$h_{b} \quad$ Buyer's holding cost per item per unit time.

$h_{v} \quad$ Vendor's holding cost per item per unit time.

$g \quad$ Vendor's unit rework cost per defective item.

$i \quad$ Vendor's fractional opportunity cost of capital per unit time.

$q(\theta)$ Vendor's capital investments require reducing the out of control probability from $\theta_{0}$ to $\theta$.

$q(S) \quad$ Capital investment required to achieve setup cost $S$ to $S_{0}$.

$\varepsilon \quad$ Percentage decrease in $\theta$ and $S$ per dollar increase in investment $q(\theta)$ and $q(S)$.

\section{Assumptions}

To expand the proposed model, we take on the following assumptions:

1. There is single vendor and single buyer is considered in this model.

2. The buyer instructions a lot of size $Q$ and the vendor manufactures $m Q$ with a finite production rate $P(P>D)$ at one setup, but ship quantity $Q$ to the buyer over $m$ times. The vendor incurs a setup cost $S$ for each production run and the buyer incurs an ordering cost $A$ for each order of quantity $Q$.

3. All imperfect objects formed are detected after the building cycle is over, and rewrite cost for imperfect items will be obtained.

4. Once the manufacture procedure shifts to an out of manage condition, the shift cannot be perceived awaiting the finish of the construction cycle, and the development incessant manufacture and a fixed percentage of the produced items are imperfect.

5. The inventory is continuously reviewed and replenished. A delivery from the vendor to the buyer uses a lot for lot plan.

6. The out of control probability $\theta$ is a continuous decision variable, and is described by a logarithmic investment function. The quality improvement and capital investment is represented by $q(\theta)=q \ln \left(\frac{\theta_{0}}{\theta}\right)$ for $\left(0<\theta \leq \theta_{0}\right)$, where $\theta_{0}$ is the current probability that the production process can go out of control and $q=\left(\frac{1}{\varepsilon}\right)$, with $\varepsilon$ denoting the percentage decrease in $\theta$ per dollar increase in $q(\theta)$. The application of the logarithmic function on quality improvement and capital investment has been proposed by many authors. (See, e.g. Hong and Hayya, [15]; Ouyang \& Chang, [21]; Ouyang et al. [22]; Porteus [29].

7. We assume that the capital investment $q(S)$, in reducing setup cost is a logarithmic function of the setup cost $S$ that is for $q(S)=q_{1} \ln \left(\frac{S_{0}}{S}\right)$ for $0<S \leq S_{0}$, where $q_{1}=\left(\frac{1}{\varepsilon}\right)$ with $\mathcal{E}$ denoting the percentage decrease in $S$ per dollar increase in $q(S)$.

8. The inventory holding cost at the buyer is higher than that at the vendor, i.e. $h_{b}>h_{v}$. 
Operations Research and Applications : An International Journal (ORAJ), Vol.3, No.2, May 2016

\section{MODEl FORMUlation}

(i) Buyer's ordering cost per unit time $=\left(\frac{D A}{Q}\right)$

(ii) Vendor's holding cot per unit time is $=\left(\frac{h_{v} Q}{2}\right)\left(m\left(1-\frac{D}{P}\right)-1+\frac{2 D}{P}\right)$

(iii) Buyer's holding cost per unit time is $=\left(\frac{h_{b} Q}{2}\right)$

(iv) Vendor's setup cost per unit time is $=\frac{D}{Q}(\mathrm{~S} / \mathrm{m})$

(v) In order to include the essence of an imperfect production process, consider the assumption made in the model proposed by Porteus [29]. The incorporated inventory model is intended for vendor manufacture situations in which, once an order is placed manufacture begins and a constant amount of units is additional to the inventory each day until the production run has been completed. The vendor produces the item in the amount $m Q$ with a given probability of $\theta$ that the process can go out of control. Porteus [29] suggested the expected number of imperfect items in a run size $m Q$ can be evaluated as $\frac{m^{2} Q^{2} \theta}{2}$. Believe $g$ is the cost of replacing a defective unit, and the manufacture amount for the supplier in a lot of $m Q$. Then it's expected defective or imperfect cost per year is given by $\frac{g m Q D \theta}{2}$.

(vi) Opportunity cost of process quality $=i q \ln \left(\frac{\theta_{0}}{\theta}\right)$

(vii) Opportunity cost of setup cost $=i q_{1} \ln \left(\frac{S_{0}}{S}\right)$

An integrated manufacture inventory model in which order quantity $Q$ and number of deliveries $m$, process quality $\theta$ and setup cost reduction $S$ are decision variables. The single vendor and single buyer total cost is given by

Minimize $T C(Q, \theta, m, S)=$ buyer's ordering cost + vendor's setup cost +vendor's holding cost+ buyer's holding cost + defective cost +opportunity cost for quality process quality + opportunity cost setup cost (From 1 to 7 )

$$
\begin{aligned}
= & \left(\frac{D A}{Q}\right)+\left(\frac{D}{Q}\right)\left[\frac{S}{m}\right]+\left(\frac{h_{v} Q}{2}\right)\left[m\left(1-\frac{D}{P}\right)-1+\frac{2 D}{P}\right]+\left(\frac{h_{b} Q}{2}\right) \\
& +\frac{g m Q D \theta}{2}+i q \ln \left(\frac{\theta_{0}}{\theta}\right)+i q_{1} \ln \left(\frac{S_{0}}{S}\right)
\end{aligned}
$$




$$
\begin{aligned}
=\left(\frac{D}{Q}\right)\left[A+\frac{S}{m}\right] & +\left(\frac{Q}{2}\right)\left(\left(m\left(1-\frac{D}{P}\right)-1+\frac{2 D}{P}\right) h_{v}+h_{b}\right)+\frac{g m D \theta Q}{2} \\
& +i q \ln \left(\frac{\theta_{0}}{\theta}\right)+i q_{1} \ln \left(\frac{S_{0}}{S}\right)
\end{aligned}
$$

Subject to $0<\theta \leq \theta_{0}$ and $0<S \leq S_{0}$.

To simplify notation, we let

$$
G=A+\frac{S}{m} \text { and } H=\left(\left(m\left(1-\frac{D}{P}\right)-1+\frac{2 D}{P}\right) h_{v}+h_{b}\right)
$$

Then the equation (8) can be reduced to

$\operatorname{Minimize} T C(Q, \theta, m, S)=\left(\frac{D G}{A}\right)+\frac{Q H}{2}+\frac{g m D \theta Q}{2}+i q \ln \left(\frac{\theta_{0}}{\theta}\right)+i q_{1} \ln \left(\frac{S_{0}}{S}\right)$

Subject to $0<\theta \leq \theta_{0}$ and $0<S \leq S_{0}$

\section{SOLUTION METHOD}

To solve the above non-linear programming problem, ignore the constraint $0<\theta \leq \theta_{0}$ and $0<S \leq S_{0}$ for the moment and minimize the total cost function over $Q, \theta, m$ and $S$ in which traditional optimization systems by taking the first order partial derivative of $T C(Q, \theta, m, S)$ with respect to $Q, \theta, m$ and $S$ are as follows

$\frac{\partial T C(Q, \theta, m, S)}{\partial Q}=-\frac{D G}{Q^{2}}+\frac{H+g m D \theta}{2}$

$\frac{\partial T C(Q, \theta, m, S)}{\partial \theta}=\frac{Q g m D}{2}-\frac{i q}{\theta}$

$\frac{\partial T C(Q, \theta, m, S)}{\partial S}=\frac{D}{Q m}-\frac{i q_{1}}{S}$

$\frac{\partial T C(Q, \theta, m, S)}{\partial m}=-\frac{D S}{Q m^{2}}+\frac{Q}{2}\left[h_{v}\left(1-\frac{D}{P}\right)+g D \theta\right]$

By investigative the second order enough conditions (SOSC) for a minimum value, it can be verified that $T C(Q, \theta, m, S)$ is a convex function of $(Q, \theta, m, S)$, since the second order partial derivative of $T C(Q, \theta, m, S)$ with respect to $m$ is positive. That is 
Operations Research and Applications : An International Journal (ORAJ), Vol.3, No.2, May 2016

$\frac{\partial^{2} T C\left(Q, \theta, m, A_{v}\right)}{\partial^{2} m}=\frac{2 D S}{Q m^{3}}>0$

From equation (14) the second order partial derivative is found to be positive. Therefore, for fixed $Q, \theta$ and $S, T C(Q, \theta, m, S)$ is convex in $m$.

Subsequently, for fixed $m$ take the first order partial derivatives of $\operatorname{TC}\left(Q, \theta, m, A_{v}\right)$ with respect to $Q, \theta$ and $S$ respectively, and obtain

$$
\begin{aligned}
& \frac{\partial T C(Q, \theta, m, S)}{\partial Q}=0 \text { we get } \\
& Q=\sqrt{\frac{2 D G}{H+g m D \theta}} \\
& \frac{\partial T C(Q, \theta, m, S)}{\partial \theta}=0 \text { we get } \\
& \theta=\frac{2 i q}{s m D Q} \\
& \frac{\partial T C(Q, \theta, m, S)}{\partial S}=0 \text { we get } \\
& A_{v}=\frac{i q_{1} Q m}{D}
\end{aligned}
$$

For fixed $m \geq 1$, by solving equations. (15) - (17), we can obtain the values of $Q, \theta$ and $S$, (denote these values by $Q^{*}, \theta^{*}$ and $S^{*}$, respectively). As the second derivative of $T C(Q, \theta, m, S)$ with respect $Q, S \quad \theta$ is positive (see Appendix), for fixed $m \geq 1$, the point $Q^{*}$, $\theta^{*}$ and $S^{*}$ is the optimal solution such that the integrated average total cost has a minimum, when the constraints $0<\theta \leq \theta_{0}$ and $0<S \leq S_{0}$ are ignored.

Now we consider the constraints $0<\theta \leq \theta_{0}$ and $0<S \leq S_{0}$ from Eq. (16) and (17), we note that $\theta^{*}$ and $S^{*}$ are positive, as $Q, q_{1}, i, D$ and $m$ are positive. Moreover, if $\theta^{\prime}<\theta_{0}$ and $S^{\prime}<S_{0}$, then $\left(Q^{\prime}, \theta^{\prime}, S^{\prime}\right)$ is an interior optimal solution for a given $m \geq 1$.

Although, if $\theta^{\prime}<\theta_{0}$ and $S^{\prime} \geq S_{0}$ then the optimal setup cost is the original setup cost, i.e. $S^{\prime}=S_{0}$. On the other hand, if $\theta^{\prime} \geq \theta_{0}$ and $S^{\prime}<S_{0}$ then the best process quality is the original process quality, i.e. $\theta^{\prime}=\theta_{0}$. Finally, if $\theta^{\prime} \geq \theta_{0}$ and $S^{\prime} \geq S_{0}$ then we should not make any investment to change the current setup and process quality, in this case, $\theta^{\prime}=\theta_{0}$ and $S^{\prime}=S_{o}$. 
Operations Research and Applications : An International Journal (ORAJ), Vol.3, No.2, May 2016

Additionally, we note that the closed form solutions for the above cases cannot be acquired through equations (15)-(17) and so does the optimal solution of the equation (9). Supplementary, based on the convexity and concavity behavior of the objective function with deference to the decision variable, the following algorithm is designed to find the optimal values of order quantity $Q$, setup cost $S$, process quality $\theta$, and total number of deliveries $m$ which minimizes the total cost $T C(Q, \theta, m, S)$. Therefore we establish the following iterative algorithm to obtain the optimal solution.

\section{Algorithm}

Step1 Let $m=1$.

Step 2 Start with $\theta=\theta_{0}$ and $S=S_{0}$.

(i) Substitute $\theta$ and $S$ into equation (15) evaluates $Q$.

(ii) Utilizing $Q$ determines $\theta$ and $S$ from equations (16) and (17).

(iii) Show again step (i) - (iii) awaiting no change occurs in the values of, $Q, \theta$, and $S$, indicate the solution by $\left(Q^{\prime}, \theta^{\prime}, S^{\prime}\right)$.

Step 3 Compare $\theta^{\prime}$ with $\theta_{0}$ and $S^{\prime}$ with $S$, respectively.

3.1 If $\theta^{\prime}<\theta_{0}$ and $S^{\prime}<S_{0}$ then the solution found in step 1 is optimal for the given $m$. We denote the optimal solution by $\left(Q_{0}, \theta_{0}, S_{0}\right)$. If $\left(Q_{0}, \theta_{0}, S_{0}\right)=\left(Q^{\prime}, \theta^{\prime}, S^{\prime}\right)$, then go to step (4), otherwise go to step (2.2).

3.2 If $\theta^{\prime}<\theta_{0}$ and $S^{\prime} \geq S_{0}$, go to step 2.3. If $\theta^{\prime} \geq \theta_{0}$ and $S^{\prime}<S_{0}$, go to step 2.4. If $\theta^{\prime} \geq \theta_{0}$ and $S^{\prime} \geq S_{0}$, then go to step 2.5 .

3.3 For given $m$, let $S^{\prime}=S_{0}$ and use equations (15) and (16) to find out the new $\left(Q^{\prime}, \theta^{\prime}\right)$ by a process similar to the one in Step 1 , the result is denoted by $(\hat{Q}, \hat{\theta})$. If $\hat{\theta}<\theta_{0}$, then the optimal solution is obtained, i.e., if $(Q, \theta, S)=\left(\hat{Q}, \hat{\theta}, S_{0}\right)$, then go to step (4), otherwise go to step (3.3.1).

3.3.1 For given $m$, let $\theta^{\prime}=\theta_{0}$ and use equation (14) to find out the new $Q^{\prime}$, then go to step (6).

3.4 For given $m$, let $\theta^{\prime}=\theta_{0}$ and use equations (15) and (17) to find out the new $(\tilde{Q}, \tilde{S})$ by a process similar to the one in Step 1 , the result is denoted by $(\tilde{Q}, \tilde{S})$ If $\tilde{S}<S_{0}$, then the optimal solution is obtained, i.e., if $(Q, \theta, S)=\left(\tilde{Q}, \tilde{S}, \theta_{0}\right)$. then go to step (4), otherwise go to step (3.4.1).

3.4.1 For given $m, S^{\prime}=S_{0}$ and use equation (15) to find out the new $Q^{\prime}$, then go to step (4).

3.5 For given $m$, let $S^{\prime}=S_{0}$ and $\theta^{\prime}=\theta_{0}$, and use equation (15) to find out the new $Q^{\prime}$, then go to step (4). 
Step 4 Use equation (9) to compute the corresponding the total $\operatorname{cost} T C\left(Q_{0}, \theta_{0}, S_{0}, m\right)$.

Step 5 If $T C\left(Q^{*}, \theta^{*}, S^{*}, m\right)=\min T C\left(Q_{0}, \theta_{0}, S_{0}, m\right)$ then $T C\left(Q_{(m)}^{*}, \theta_{(m)}^{*}, S_{(m)}^{*}, m\right)$ is the optimal solution for fixed $m$.

Step 6 Set $m=m+1$, repeat step 2 and 5 to get $T C\left(Q_{(m)}^{*}, \theta_{(m)}^{*}, S_{(m)}^{*}, m\right)$.

Step 7 If $T C\left(Q_{(m)}^{*}, \theta_{(m)}^{*}, S_{(m)}^{*}, m\right) \geq T C\left(Q_{(m+1)}^{*}, \theta_{(m+1)}^{*}, S_{(m+1)}^{*}, m+1\right)$, then go to step 6 , otherwise go to step 8.

Step $8 \operatorname{Set}\left(Q^{*}, \theta^{*}, S^{*} m^{*}\right)=\left(Q_{(m+1)}^{*}, \theta_{(m+1)}^{*}, S_{(m+1)}^{*}, m+1\right)$, then $\left(Q^{*}, \theta^{*}, S^{*} m^{*}\right)$ is the optimal solutions.

\section{NUMERICAL EXAMPLE}

In arrange to demonstrate the above solution method, let us consider a inventory system with the following data $D=1000$ units/year, $P=3200$ units/year, $A=\$ 25 /$ order, $S_{0}=\$ 400 /$ setup, $h_{b}=\$ 5$ units/year, $h_{v}=\$ 4$ units/year, $g=\$ 15 /$ defective units, $\theta_{0}=0.0002$. Besides, we take $q=400, q_{1}=1500, i=0.1$. The optimal solutions from table (1), can be read off as order quantity $Q^{*}=110$ units, number of deliveries $m^{*}=1$, process quality $\theta^{*}=0.000048$ and the corresponding total cost $T C^{*}=1296$. The result of solution procedure is summarized in table (1). A graphical representation is presented to show the convexity of $T C\left(Q^{*}, \theta^{*}, S^{*} m^{*}\right)$ in figure (1) and the graphical representation of the total cost for different number of deliveries $m$ is shown in figures (2).

Table (1) Summary of optimal solution

\begin{tabular}{|l|l|l|l|l|}
\hline$m$ & $Q$ & $\theta$ & $S$ & TC \\
\hline 1 & 110 & 0.000048 & 17 & 1296 \\
\hline 2 & 88 & 0.000030 & 26 & 1353 \\
\hline 3 & 75 & 0.000023 & 34 & 1420 \\
\hline 4 & 67 & 0.000019 & 40 & 1486 \\
\hline
\end{tabular}

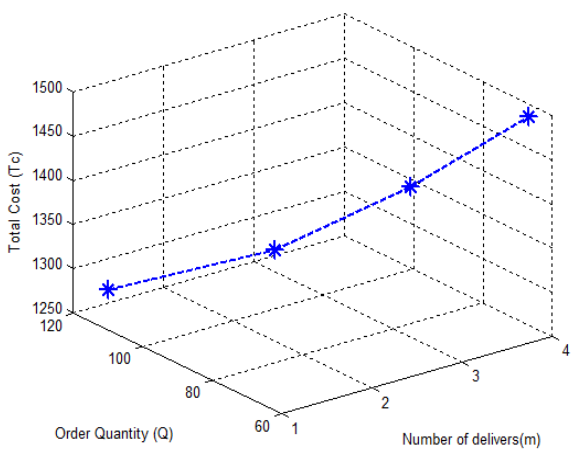

Figure (1) Graph representing the convexity of TC 


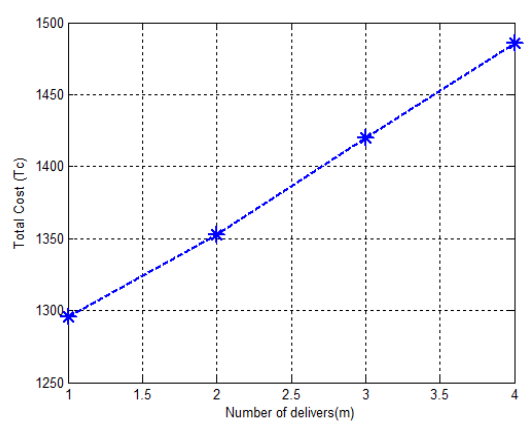

Figure (2) Graphical representation of the optimal solution in TC

\section{Conclusion}

The main idea of this paper is to present the single vendor single buyer integrated production inventory model with effectively rising investment to reduce the setup cost and process quality. This model is to diminish the addition of the ordering/setup cost, holding cost, investment for process quality by simultaneously optimizing order quantity, setup cost, process quality and the number of deliveries. In our model, the capital investment in setup cost reduction and process quality is assumed to be a logarithmic function. The major intend of this paper is to minimize the total cost. A solution method is urbanized to locate the best solution. The behavior of the model is presented graphically. The result is illustrated with the help of a numerical example.

\section{ACKNOWLEDGEMENT}

We express thank you, especially much for the comments and suggestions. The author also wishes to thank the journal publishing editor for their supportive suggestions, which have led to an important development in the earlier version of the revised manuscript. The first author research work is supported by DST INSPIRE Fellowship, Ministry of Science and Technology, Government of India under the grant no. DST/INSPIRE Fellowship/2011/413A dated 22.12.2015 and UGC-SAP, Department of Mathematics, Gandhigram Rural Institute - Deemed University, Gandhigram - 624302, Tamilnadu, India.

\section{REFERENCES}

[1] Banerjee, A., "A joint economic-lot-size model for purchaser and vendor," Decision Sciences, Vol. 17, No. 5, pp. 292-311 (1986).

[2] Cardenas-Barron, L. E. (2000) "Observation on Economic production quantity model for items with imperfect quality". International Journal of Production Economic, Vol. 67, No. 2, pp. 59-64.

[3] Chan, W. M., Ibrahim, R. N. \& Lochert, P.B. (2003) "A new EPQ model: integrating lower pricing rework and reject situations". Production Planning \&Control, Vol.14, No. 7, pp.588-595.

[4] Goyal S. K. (1995) "A one-vendor multi-buyer integrated inventory model: A comment". European Journal of the Operational Research, Vol. 82, No.1, pp. 209-210.

[5] Goyal, S. K. \& Gupta, Y. P. (1989) "Integrated inventory models: the buyer vendor coordination," European Journal of Operational Research, Vol. 41,No. 3, pp. 236-241 (1989). 
Operations Research and Applications : An International Journal (ORAJ), Vol.3, No.2, May 2016

[6] Goyal, S. K. \& Nebebe, F. (2000)"Determination of economic production-shipment policy for a single-vendor-single-buyer system". European Journal of the Operational Research, Vol. 121, No. 1, pp. 175-178.

[7] Goyal, S. K. \& Srinivasan, G. (1992) "The individually responsible and rational decision approach to economic lot sizes for one vendor and many purchasers: a comment," Decision Sciences, Vol. 23, No. 3, pp. 777-784.

[8] Goyal, S. K. (1976) “An integrated inventory model for a single supplier-single customer problem". International Journal of Production Research, Vol. 15, No. 1, pp. 107-111.

[9] Goyal, S. K. (1977) "Integrated inventory model for a single supplier-single customer problem," International Journal of Production Research, Vol. 15, No. 1, pp. 107-111

[10] Goyal, S. K. (1988) "A joint economic-lot-size model for purchaser and vendor: a comment," Decision Sciences, Vol. 19, No. 1, pp. 236-241.

[11] Ha, D. \& Kim, S. (1997) "Implementation of JIT purchasing: An integrated approach". Production Planning \& Control, Vol. 8, No. 2, pp.152-157.

[12] Hill, R. M. (1997) "The single-vendor single-buyer integrated production inventory model with a generalized policy". European Journal of Operational Research, Vol. 97, No. 3, pp. 493-499

[13] Hill, R. M. (1999) "The optimal production and shipment policy for the single-vendor singlebuyer integrated production-inventory problem". International Journal o production Research, Vol. 37, No. 11, pp. 2463-2475.

[14] Hofmann, C. (1998) "Investments in modern production technology and the cash flow-oriented EPQ-model". International Journal of Production Economics, Vol. 54, No. 3, pp.193-206.

[15] Hong, J.D. \& Hayya, J. C. (1995) "Joint investment in quality improvement and setup reduction". Computers and Operations Research, Vol. 22, no, 6. pp. 567-574.

[16] Kelle, P. F., Al-khateeb, F. \& Miller, P.A. (2003) "Partnership and negotiation support by joint optimal ordering/setup policies for JIT". International Journal of Production Economics, Vol. 8182, No.11, pp. 431-44.

[17] Keller, G. \& Noori, H. (1988) "Impact if investing in quality improvement on the lost size model". International Journal of Management Sciences, Vol.15, No.4, pp. 595-601.

[18] Lin, C. \& Lin, Y. (2004) "A joint EOQ model for supplier and retailer with deteriorating items". Asia-Pacific Journal of Operational Research, Vol. 21, No.4, pp. 163-178.

[19] Lu, L. (1995). "A one- vendor multi-buyer integrated inventory model". European Journal of operational Research, Vol. 81, No.2, pp. 312-323.

[20] Nasri, F., Affisco, J. F. \& Paknejad, M. T. (1990)"Setup cost reduction in an inventory model with finite range stochastic lead times". International Journal of Production Research, Vol. 28, No.1, 99-212.

[21] Ouyang, L. Y. \& Chang, H. C. (2000) "Impact of investing in quality improvement on (Q, r, L) model involving imperfect production process". Production Planning \&Control, Vol. 11, No. 6, pp. 598-607.

[22] Ouyang, L. Y., Chen, C. K. \& Chang H. C (2002) "Quality improvement, setup cost and lead time reductions in lot size reorder point models with an imperfect production process". Computer \& Operations Research, Vol. 29, No. 12, pp. 1701-1717.

[23] Paknejad, M. J. \& Affisco J. F (1988) "Setup cost reduction in the classical production lot size with backorders model". Proceedings of the Northeast Decision Sciences Institute, pp.82-86.

[24] Paknejad, M. J. \& Affisco J. F (1987) "The effect of investment in new technology on optimal batch quantity". Proceedings of the Northeast Decision Sciences Institute, DSI, RI, USA, pp. 118120.

[25] Paknejad, M. J. \& Affisco J. F (1991) "An analysis of setup cost reduction in a two stage system". Mathematical Methods of Operations Research, Vol.35, No.6, pp.505-532.

[26] Pan, J. C. H. \& Yang, J. S. (2002) "A study of an integrated inventory with controllable lead time". International Journal of Production Research, Vol. 40, No.5, pp. 1263-1273.

[27] Porteus, E. (1986) "Investing in new parameter values in the discounted EOQ model". Naval Research Logistic Quarterly, Vol. 34, No.1, pp.137-144. 
Operations Research and Applications : An International Journal (ORAJ), Vol.3, No.2, May 2016

[28] Porteus, E. (1985) "Investing in reduced setups in the EOQ model". Management Sciences, Vol. 31, No.8, pp.998-1010.

[29] Porteus, E. L (1986) "Optimal lot sizing, process quality improvement and setup cost reduction". Operations Research, Vol. 34, No.1, pp.137-144.

[30] Rosenblatt, M. J. \& Lee, H. L. (1986) "Economic production cycles with imperfect production processes". IIE Transactions, Vol. 18, No.1, pp. 48-55.

[31] Salameh, M. K. \& Jaber, M. Y. (2000) "Economic order quantity model for items with imperfect quality". International Journal of Production Economics, Vol. 64, No. (1-3), pp. 59-64.

[32] Sarker, B. R. \& Coates, E. R. (1997) "Manufacturing setup cost reduction under variable lead times and finite opportunities for investment". International Journal of Production Economics, Vol. 49, No. 3, pp. 237-247.

[33] Vandana \& B. K. Sharma (2015) "An inventory model for non-instantaneous deteriorating items with quadratic demand rate and shortages under trade credit policy". Journal of Applied Analysis and Computation, in press.

[34] Vandana \& B. K. Sharma (2016) "An EOQ model for retailer's partial permissible delay in payment linked to order quantity with shortages". Mathematics and Computers in Simulation, in press.

[35] Vandana \& Sharma, B. K. (2015) "An EPQ inventory model for non-instantaneous deteriorating items under trade credit policy". International Journal of Mathematical Sciences and Engineering Applications, Vol. 9, No. I, pp. 179-188.

\section{Appendix}

The second order partial derivative of $T C(Q, \theta, m, S)$ with respect to $Q$ is given by

$$
\frac{\partial^{2} T C(Q, \theta, m, S)}{\partial \mathrm{Q}^{2}}=\frac{2 D G}{Q^{3}}>0
$$

The second order partial derivative of $T C(Q, \theta, m, S)$ with respect to $\theta$ is given by

$$
\frac{\partial^{2} T C(Q, \theta, m, S)}{\partial \theta^{2}}=\frac{i q}{\theta^{2}}>0 \text {. }
$$

The second order partial derivative of with respect to $S$ is given by

$$
\frac{\partial^{2} T C(Q, \theta, m, S)}{\partial \mathrm{S}^{2}}=\frac{i q_{1}}{S^{2}}>0 \text {. }
$$


Operations Research and Applications : An International Journal (ORAJ), Vol.3, No.2, May 2016

\section{Biographical Notes}

M. Vijayashree is a full time research scholar in the Department of Mathematics at The Gandhigram Rural Institute - Deemed University, Gandhigram, India. She received her B.Sc in Mathematics from M.V.M Govt Women's Arts College, Dindigul, Tamilnadu, India in 2007 and M.Sc. Tech (IMCA) in Industrial Mathematics with Computer Applications from The Gandhigram Rural InstituteDeemed University, Gandhigrm, Dindigul, Tamilnadu, India in 2010. Currently, she is a Senior Research Fellow under DST INSPIRE, New Delhi, in the Department of Mathematics, The Gandhigram Rural Institute - Deemed University, Gandhigram-624302, Dindigul, Tamilnadu, India. Her research interests include the following fields: Operations Research, Inventory Management and Control, Supply Chain Management.

R. Uthayakumar is currently a Professor in the Department of Mathematics at The Gandhigram Rural Institute - Deemed University, Gandhigram, India. He received his M.Sc in Mathematics from American College, Madurai, India in 1989 and Ph.D in Mathematics from The Gandhigram Rural Institute - Deemed University, Gandhigram, India in 2000. He has published about 121 papers in international and national journals. His research interests include the following fields: Operations

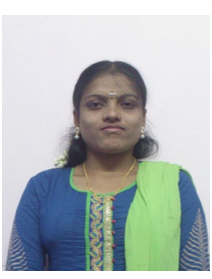
Research, Industrial Engineering and Fractal Analysis Fuzzy Spaces, Inventory Model and Supply Chain Management. 